\title{
Educação financeira e educação socioemocional integradas para discutir armadilhas psicológicas em decisões financeiras \\ Integrating financial and socioemotional education to discuss psychological pitfalls in financial decisions
}

\section{Educación financiera y educación socioemocional integradas para discutir los escollos psicológicos en las decisiones financieras}

\author{
Luciene dos Santos Silva ${ }^{1}$ \\ Instituto Federal de São Paulo \\ https://orcid.org/0000-0001-8480-6156 \\ Diva Valério Novaes ${ }^{2}$ \\ Instituto Federal de São Paulo \\ https://orcid.org/0000-0002-4000-1839
}

\begin{abstract}
Resumo
Descreveremos o desenvolvimento de uma sequência didática elaborada para apresentar conceitos de educação financeira e educação socioemocional a alunos do primeiro ano do ensino médio de uma escola no litoral norte de São Paulo. A inserção, no contexto de vida dos alunos, de conceitos de planejamento financeiro, custo de oportunidade, relatividade financeira, autogestão, porcentagem, juros simples e juros compostos possibilitou aprendizado significativo, promovendo reflexão sobre armadilhas psicológicas envolvidas nas decisões financeiras e no mundo econômico. Discutimos maneiras de lidar com o dinheiro de forma equilibrada e consciente. Os registros e as rodas de conversa apontaram que houve percepção dos principais erros financeiros e indicaram aquisição de criticidade nos aspectos econômicos.
\end{abstract}

Palavras-chave: Autoconhecimento, Gestão das emoções, Saúde financeira e ambiental, Metodologia ativa.

\footnotetext{
${ }^{1}$ lucieneifsp@ hotmail.com

2 novaes.diva@gmail.com
} 


\begin{abstract}
This article describes the application of a teaching sequence designed to introduce concepts of financial and socioemotional education to $1^{\text {st }}$-grade high school students on the northern coast of the state of São Paulo, Brazil. The introduction of concepts of financial planning, opportunity cost, financial relativity, self-management, percentages, and simple and compound interest in real-life contexts commonly experienced by the students promoted significant learning, triggering reflections on the psychological pitfalls involved in financial decisions and the economic world. Ways of dealing with money in a balanced, conscious fashion were discussed. Classroom records and group conversations revealed gains in perception of major financial mistakes and acquisition of critical thinking in economic issues.
\end{abstract}

Keywords: Self-knowledge, Emotion management, Financial and environmental health, Active methodology.

\title{
Resumen
}

Abordamos el desarrollo de una secuencia didáctica, con el objetivo de insertar conceptos de educación financiera y educación socioemocional para estudiantes de 1er año de secundaria de una escuela de la costa norte del estado de São Paulo. La inserción de conceptos de planificación financiera, costo de oportunidad, relatividad financiera, autogestión, porcentaje, interés simple e interés compuesto, en el contexto de la vida de los estudiantes, posibilitó un aprendizaje significativo, promovió la reflexión sobre las trampas psicológicas involucradas en las decisiones financieras y en el mundo económico. Discutimos formas de lidiar con el dinero de manera equilibrada y consciente. Los registros y círculos de conversación señalaron que existía una percepción de los principales errores financieros y la adquisición de criticidad en los aspectos económicos. 
Palabras clave: Conocimiento de sí mismo, Manejo de emociones, Salud financiera y ambiental, Metodología activa. 


\section{Educação financeira e educação socioemocional integradas para discutir armadilhas psicológicas em decisões financeiras}

A educação financeira é extremamente importante por capacitar os estudantes a refletir melhor sobre suas relações com o dinheiro e minimizar a possibilidade de descontrole financeiro. O desenvolvimento desta pesquisa tem por base a literatura sobre economia comportamental, bem como notícias veiculadas na mídia e no que propõe a legislação educacional brasileira, aportes estes que contribuem para a educação financeira no âmbito escolar.

Em 2015, uma pesquisa do Indicador de Educação Financeira (IndEF) 2014, elaborado por Serasa Consumidor (braço de Serasa Experian voltado ao consumidor) e de IBOPE Inteligência revelou que, no Brasil, jovens de 16 a 24 anos são os que têm menos controle de sua vida financeira.

De acordo com a pesquisa, que entrevistou 2002 consumidores acima de 16 anos, em todo o Brasil, no primeiro semestre de 2014, $40 \%$ admitem não manter a vida financeira sob controle. Quanto mais idade, maior é o percentual de pessoas que afirma manter o controle dos gastos: 62\%, entre 25 e 34 anos, 66\%, entre 35 e 44 anos, $67 \%$, entre 45 e 54 anos, e $75 \%$, entre 55 e mais. (Serasa Consumidor, 2015)

Segundo Serasa Experian (2019), os adultos de 36 a 40 anos são os que apresentam maior índice de inadimplência (47,2\%). De todo modo, muitos são os casos e faixas etárias de inadimplentes, o que justifica a necessidade de educação financeira para preparar as pessoas para lidar com situações financeiras e contribuir para a aquisição de autocontrole em suas finanças. No entanto, o que nos chamou atenção foi o aumento de inadimplentes idosos e a queda na taxa de inadimplentes entre os jovens em recente biênio: de 33,5\% em 2016 para $31,6 \%$ em 2018.

Percebe-se atualmente que houve redução nos índices de jovens inadimplentes, embora com aumento na faixa de 36 a 40 anos. Supomos que a inserção da educação financeira no currículo da educação básica tenha gerado resultados positivos. A partir de 2015, foram 
distribuídos livros sobre educação financeira elaborados pela Estratégia Nacional de Educação Financeira (ENEF). Muitas escolas tiveram acesso ao material didático composto de atividades sobre o tema e desde então notam-se reduções nos índices entre o público jovem.

O alto índice mencionado por Serasa Experian (2019) revela falta de controle financeiro, com muitos idosos se endividando cada vez mais. Saber administrar e lidar com situações financeiras é fundamental para não cair nas armadilhas do consumismo. Vale observar a diferença entre consumo e consumismo. Nós necessitamos consumir pois não produzimos tudo que necessitamos. A abundância é boa, mas excesso e desperdício são prejudiciais. Consumir além do necessário pode prejudicar a saúde financeira e o ambiente natural. Os nossos desejos são ilimitados, mas os recursos naturais da Terra não são.

Para Bauman (2008), o consumismo é a economia do engano, que aposta na irracionalidade dos consumidores e não em suas estimativas sóbrias e bem-informadas sobre suas necessidades genuínas. Segundo Layard (2008), "Querer” mantém nos mais motivados do que "Ter". Depois que temos o bem perde interesse e passamos a querer outros. Esse fato conduz à "esteira hedonista", na qual, necessitamos comprar cada vez mais para sentir a mesma gratificação. Reconhecer em nós esta estrutura fará compreender a engrenagem do consumismo e refletir em nossas necessidades essenciais. A ausência destas necessidades provoca patologias e o atendimento delas é o que pode promover o bem-estar que todo ser humano deseja.

Dessa forma, além de não saberem gerir suas finanças, as pessoas podem não saber lidar com suas emoções, por não disporem de autodomínio sobre suas ações. Nota-se que em outros países ocorre esse mesmo problema:

[...] uma pesquisa realizada sob os auspícios conjuntos da Financial Services Authority (órgão responsável pela regulação do sistema financeiro do Reino Unido) e da Universidade de Bristol descobriu que a geração entre 18 e 40 anos de idade (ou seja, a primeira geração adulta criada amadurecendo numa sociedade de consumo plenamente desenvolvida) é incapaz de administrar suas dívidas ou acumular algo acima de um nível "alarmante baixo" de poupanças: só 30\% dos indivíduos dessa geração guardaram algum dinheiro para compras futuras, enquanto $42 \%$ nada fizeram para garantir alguma 
perspectiva de pensão e $24 \%$ dos jovens (mas apenas $11 \%$ das pessoas acima de 50 anos e $6 \%$ daquelas acima de 60) estão no vermelho em suas contas bancárias. (Bauman, 2008, p. 103-104)

Tais dados revelam a importância da educação financeira nas escolas, pois cada vez há mais jovens e adultos que enfrentam dificuldades em administrar seus gastos. Segundo Ariely e Kreisler (2019) e outros economistas comportamentais, tendemos a seguir sinais enganadores e até manipuladores para definir valor em nossas decisões financeiras. Alguns desses sinais devem-se a forças internas de nosso funcionamento cerebral e outros a forças externas. Em decorrência, há quem lucre quando interpretamos incorretamente o verdadeiro valor das coisas.

Por essa razão, defendemos a promoção do ensino e aprendizagem desse tema, com inserção da gestão emocional juntamente com a educação financeira, de modo a permitir ao estudante desde cedo saber lidar com o dinheiro, ser capaz de administrá-lo e evitar o endividamento em níveis prejudiciais à saúde financeira. A longo prazo, pode-se formar um adulto financeiramente consciente, capaz de lidar a contento com situações financeiras e gerenciar as emoções envolvidas nestas questões. Logo, a educação financeira é de extrema relevância e necessita ser inserida no cotidiano dos alunos, a fim de proporcionar-lhes uma visão crítica de questões socioeconômicas.

Administrar o dinheiro, saber lidar com o autocontrole e dispor de autoconhecimento são questões relacionadas. Como tomar decisões financeiras se não houver equilíbrio emocional, bem como conhecimento das reais necessidades? Para refletir sobre essa questão, apoiamo-nos em estudos de psicologia e economia comportamental, áreas fundamentais para lidar com o âmbito emocional e o financeiro.

Segundo Ariely e Kreisler (2019), autores de A psicologia do dinheiro, as armadilhas psicológicas por trás de nossas decisões financeiras valem-se do funcionamento cerebral humano e de relações com o marketing. Esses autores afirmam que grande parte das pessoas 
pensam em dinheiro todo o tempo, preocupando-se com sua quantidade, com as formas de gastá-lo e guardá-lo e com quanto o vizinho ganha e gasta. No entanto, outras questões menos visíveis também fazem parte desse cenário. Pensar em dinheiro pode ser extremamente cansativo e estressante, gerar conflitos e induzir a más decisões.

Para Ariely e Kreisler (2019, p. 11), "nos Estados Unidos, o dinheiro é o maior motivo de divórcios e a causa número um de estresse. No Brasil, o dinheiro também é uma das principais causas de estresse, juntamente com o medo da violência e do desemprego". Os autores definem dinheiro como uma representação de valor, que permite a troca por outro bem. Ele tem a característica de ser genérico, permitindo sua troca por quase tudo. Além disso, é divisível e intercambiável (o que lhe permite ser substituído por outra nota do mesmo valor ou notas que perfaçam montante equivalente), além de ser armazenável (ou seja, utilizável tanto no presente quanto no futuro).

O objetivo real da educação financeira está no sentido de criar uma mentalidade adequada e saudável em relação ao bom uso do dinheiro na aquisição de bens e serviços pelos consumidores, além das decisões nas aplicações financeiras. (Borges, 2014, p. 1)

A atenção dada a esse tema vem aumentando nos últimos anos, pois a crescente carência de adequado gerenciamento financeiro traz consigo uma série de problemas sociais e de saúde física e emocional que afetam a vida pessoal e profissional das pessoas. Reflete ainda no meio ambiente natural, uma vez que o modo consumista de viver, provoca um aumento na produção e exploração de recursos naturais, uma das principais causas do intenso processo de degradação ambiental que se presencia nos dias de hoje. Thaler e Sunstein (2019) salientam, com base em pesquisas, que podemos fazer escolhas ruins que não faríamos se dispuséssemos de todas as informações necessárias (ou seja, se fôssemos oniscientes) e de capacidades cognitivas desenvolvidas, tais como total autocontrole. No entanto, somos mais suscetíveis a erros de escolha do que nos dispomos a admitir. A fim de melhorar nossa capacidade decisória, esses autores sugerem a prática do nudge, termo inglês que designa um empurrãozinho, não uma 
ordem. Um exemplo de nudge com fins dietários seria colocar as frutas em posição bem visível e os doces mais afastados no refeitório escolar das crianças. As pesquisas revelam que elas se alimentam mais saudavelmente dessa forma, embora os doces continuem a seu alcance: muda apenas a disposição. Proibir junk food, por sua vez, não é nudge. Se as pessoas não estão fazendo escolhas perfeitas, promover algumas mudanças na arquitetura de escolhas pode melhorar sua vida levando em conta suas próprias preferências, e não as de algum burocrata com mais conhecimento sobre certos aspectos do funcionamento humano. Thaler e Sunstein (2019) afirmam que pais, professores, empresas e médicos podem tornar-se uma espécie de "arquitetos de escolhas", para criar ambientes que estimulem boas decisões. Acreditamos que a educação financeira, se associada à educação socioemocional, pode funcionar como um nudge na vida dos estudantes, por fornecer mais informações e colaborações para a autogestão.

A partir de 2010, surgiram organizações que observaram a importância de inserir educação financeira no processo educativo escolar, e esta foi incluída na legislação educacional. A ENEF foi criada em 2010 a partir do Comitê Nacional de Educação Financeira (CONEF), por meio do qual foram planejados modos de inserção da educação financeira nas escolas, desenvolvendo-se programas para orientar os jovens financeiramente. Antes de 2010, pouco se falava sobre educação financeira na educação básica, mas hoje há órgãos que se reuniram em um comitê voltado a preparar e educar as pessoas financeiramente.

A Base Nacional Comum Curricular (BNCC) (Brasil, 2018) apresenta uma nova forma de ver e abordar os conteúdos obrigatórios, orientando à ligação com a realidade dos alunos e propondo formas de relacionar conteúdos com aplicações práticas, de modo a instigar o aluno a participar na aula, visto que o foco proposto está no protagonismo do aluno. No ensino médio, onde desenvolvemos a atividade aqui descrita, enfatiza-se a aplicação do conteúdo à realidade dos alunos, para que desenvolvam habilidades como raciocinar, representar, argumentar e comunicar, de modo a aprenderem por meio de discussões e a desenvolverem representações. 
Segundo a BNCC (Brasil, 2018), um dos desafios para a aprendizagem de matemática no ensino médio é exatamente proporcionar aos estudantes a visão de que ela não é um conjunto de regras e técnicas, mas faz parte de nossa cultura e de nossa história. A matemática vai além das regras e técnicas. Compõe-se de conteúdos que estão imersos em nosso dia a dia. No ensino médio, a orientação é aprofundar as habilidades abordadas no ensino fundamental e promover sua aplicação no cotidiano.

Na BNCC (Brasil, 2018), a educação financeira ganhou enfoque distinto. Esta legislação propõe afastar-se da matemática financeira pura, dando lugar à formação de cidadãos mais capazes de tomar boas decisões ao lidarem com situações financeiras, tanto na vida pessoal quanto no convívio social, o que envolve responsabilidades com as questões ambientais advindas do consumismo. Ou seja, sai de cena a matemática financeira pura e entra a educação financeira, em articulação com outras áreas do conhecimento, tais como Ciências Humanas e Sociais aplicadas. Na descrição da competência específica 2 para o ensino médio consta:

Articular conhecimentos matemáticos ao propor e/ou participar de ações para investigar desafios do mundo contemporâneo e tomar decisões éticas e socialmente responsáveis, com base na análise de problemas de urgência social, como os voltados a situações de saúde, sustentabilidade, das implicações da tecnologia no mundo do trabalho, entre outros, recorrendo a conceitos, procedimentos e linguagens próprios da Matemática. (EM13MAT203) Planejar e executar ações envolvendo a criação e a utilização de aplicativos, jogos (digitais ou não), planilhas para o controle de orçamento familiar, simuladores de cálculos de juros compostos, dentre outros, para aplicar conceitos matemáticos e tomar decisões. (Brasil, p. 526, 2018).

Entendemos que abordar temas do cotidiano dos alunos possibilita a interação com o conteúdo e o aprendizado significativo. No que se refere a temas da educação financeira, isso é essencial.

O objetivo deste trabalho foi elaborar uma sequência didática para abordar a educação financeira integrada à gestão das emoções, por meio da educação socioemocional, analisando 
as contribuições dessa inserção no primeiro ano do ensino médio no espaço destinado ao processo de ensino e aprendizagem de matemática.

Este artigo foi produzido no âmbito da linha de pesquisa de Formação de Professores do Mestrado Profissional em Ensino de Ciências e Matemática da instituição pública em que atuamos, inserido em um Grupo de Pesquisa em Políticas Públicas para a Educação Básica cadastrado no CNPq, coordenado pela segunda autora. Trata-se de uma dissertação de mestrado profissional em andamento, aprovada em banca de qualificação.

\section{Relatividade financeira}

A atividade que discutiremos apresenta o conceito da relatividade financeira e situações de consumo, segundo Ariely e Kreisler (2019), tais como a comparação de uma mercadoria com outra parecida.

Um exemplo mencionado por esses autores é a compra de uma camisa que custava $\mathrm{R} \$ 200,00$ e passou a custar $\mathrm{R} \$ 120,00$ na promoção com $40 \%$ de desconto. Muitas vezes, não conseguindo avaliar o valor de bens e serviços, avaliamos o preço com base no valor relativo ao preço original informado: $\mathrm{R} \$ 120,00$ é relativamente barato se comparado com $\mathrm{R} \$ 200,00$. Sentimo-nos especiais, e até espertos, por economizarmos $\mathrm{R} \$ 80,00$. No entanto, faz-se necessário comparar R \$120,00 com zero, ou com outras coisas que poderíamos comprar com $\mathrm{R} \$ 120,00$, ou seja, analisar o custo de oportunidade dos R\$120,00 que estão sendo gastos, e não os $\mathrm{R} \$ 80,00$ de desconto. Neste caso, somos levados a comparar o preço antigo (R $\$ 200,00)$ com o atual ( $\mathrm{R} \$ 120,00)$, por tendência a fazer a escolha mais fácil. Por exemplo, diante de dois produtos, um deles em promoção e o outro não, tendemos a escolher o de menor preço, por ser a escolha mais fácil frente ao trabalho de definir o valor real de ambos.

Segundo Kahneman (2012), caímos em armadilhas psicológicas porque nosso cérebro é preparado para economizar energia e tem dois modos de funcionamento: o sistema 1 opera de maneira automática e rápida, com pouco ou nenhum esforço e nenhuma percepção de 
controle voluntário, ao passo que o sistema 2 é lento, raciocinador, faz escolhas e decide o que pensar e o que fazer a respeito de algo. As ações do sistema 2 são interrompidas quando a atenção é indevidamente desviada. Assim, o melhor que podemos fazer é aprender e reconhecer situações em que os enganos são prováveis e nos esforçarmos para evitá-los quando há coisas significativas em jogo.

Devemos usar estratégias para lidar com nossos conflitos e saber reconhecê-los. Segundo Thaler e Shefrin (1981, p.398) "Dieters try not to keep cheesecake in the refrigerator and will refuse invitations to lavish dinner parties; problem gamblers avoid Las Vegas." Ou seja, devemos criar regras para lidar com nossos conflitos e tentar administrá-los. Por exemplo, evitar ir a jantares quando se está de dieta como os jogadores evitam ir a Las Vegas, pois não conseguem se controlar. São regras que se estabelecidas como rotina podem se tornar um hábito, (Thaler e Shefrin, 1981).

Pode-se dizer que estas sugestões funcionam como um nudge, nos termos de Thaler e Sunstein (2019). Este é um dos objetivos deste trabalho: atuarmos como "arquitetos de escolhas", para criar ambientes que estimulem boas decisões financeiras entre os adolescentes.

Para Ariely e Kreisler (2019, p. 50), “o fato é que a relatividade se infiltra em todos os aspectos de nossa vida e de forma poderosa". Seja em seu desenvolvimento profissional ou pessoal, comparar se outros estão melhores ou piores que você, se estão mais felizes ou mais prósperos, não é saudável, podendo gerar sensações desagradáveis e baixa autoestima, bem como instigar a aquisição de produtos acima da capacidade de pagar por eles, somente para ter o mesmo que outros, ainda que não seja uma necessidade para si. Frequentemente comparamos o melhor do outro (ou pelo menos o que vemos como melhor) com o pior de nós e não notamos que não temos acesso a toda a realidade vivida pelo outro. A importância de conhecer a relatividade, seja financeira ou em outras áreas da vida, está na possibilidade de utilizá-la a nosso favor, como discutido no exemplo da compra da camisa. 


\section{Procedimentos metodológicos}

A pesquisa, de cunho qualitativo, utiliza metodologia ativa na forma de um jogo que aborda a gestão das emoções e a sala de aula invertida. Inverter o processo, para Bacich e Moran (2018), pressupõe que o professor atue como mediador, deixando a responsabilidade do

conhecimento básico a cargo dos alunos, com forte componente do trabalho em grupo. À medida que o conhecimento avança, o professor intervém quando se fizer necessário.

Elaboramos uma sequência didática composta de sete atividades, das quais selecionamos uma para discussão neste artigo: a atividade 3, intitulada Autogestão. As demais compõem o produto final da dissertação de mestrado profissional, em desenvolvimento, da primeira autora. A sequência didática foi aprovada pelo Comitê de Ética no início de dezembro de 2019, com o parecer consubstanciado número 3.753 .895 e aplicada logo após esta aprovação. Foram utilizadas $2 \mathrm{~h} / \mathrm{a}$ para atividade 3 discutida neste artigo (uma hora para o trabalho nas duplas e uma para roda de conversa), com a participação de 24 alunos do primeiro ano do ensino médio integrado ao de técnico em administração. $\mathrm{O}$ conjunto de todas as atividades buscou trabalhar conceitos como planejamento financeiro, custo de oportunidade, relatividade financeira, autogestão, porcentagem, juros simples e juros compostos.

Ao final de cada atividade, procedeu-se a uma roda de conversa para discutir, refletir e socializar com o grupo a percepção de cada participante sobre os temas envolvidos nas atividades. As observações da roda de conversa foram também utilizadas como ferramenta de análise pela professora pesquisadora. Para Cracasso (2016), as regras da roda de conversa como metodologia de ensino são impactantes, trazendo ao adolescente oportunidades de controlar seus impulsos, esperar sua vez de manifestar-se, flexibilizar dificuldades pela troca de ideias e ampliar seu repertório linguístico ao se expressar. 
A atividade 3 - Autogestão utiliza um jogo de cartas que apresenta uma situação fictícia de consumo intitulada "Conquiste seu sonho!" (Figura 1). Na Fase I da atividade, cabe a cada participante ler a carta, decidir entre aceitá-la ou não e registrar sua decisão (“sim” ou "não") no quadro fornecido. O jogo busca trabalhar a autogestão, a relatividade e o custo de oportunidade, como definidos por Ariely e Kreisler (2019). As cartas foram elaboradas para que os estudantes pudessem se sentir em uma situação de ação frente a possíveis comportamentos financeiros. Cada carta simula uma possível armadilha psicológica e o jogo visa levar os alunos a refletir se caíram ou não nas armadilhas e em quantas.

\section{Figura 1.}

Atividade 3 - Autogestão. Cartas do jogo “Conquiste seu sonho!” (Ariely e Kreisler, 2019).

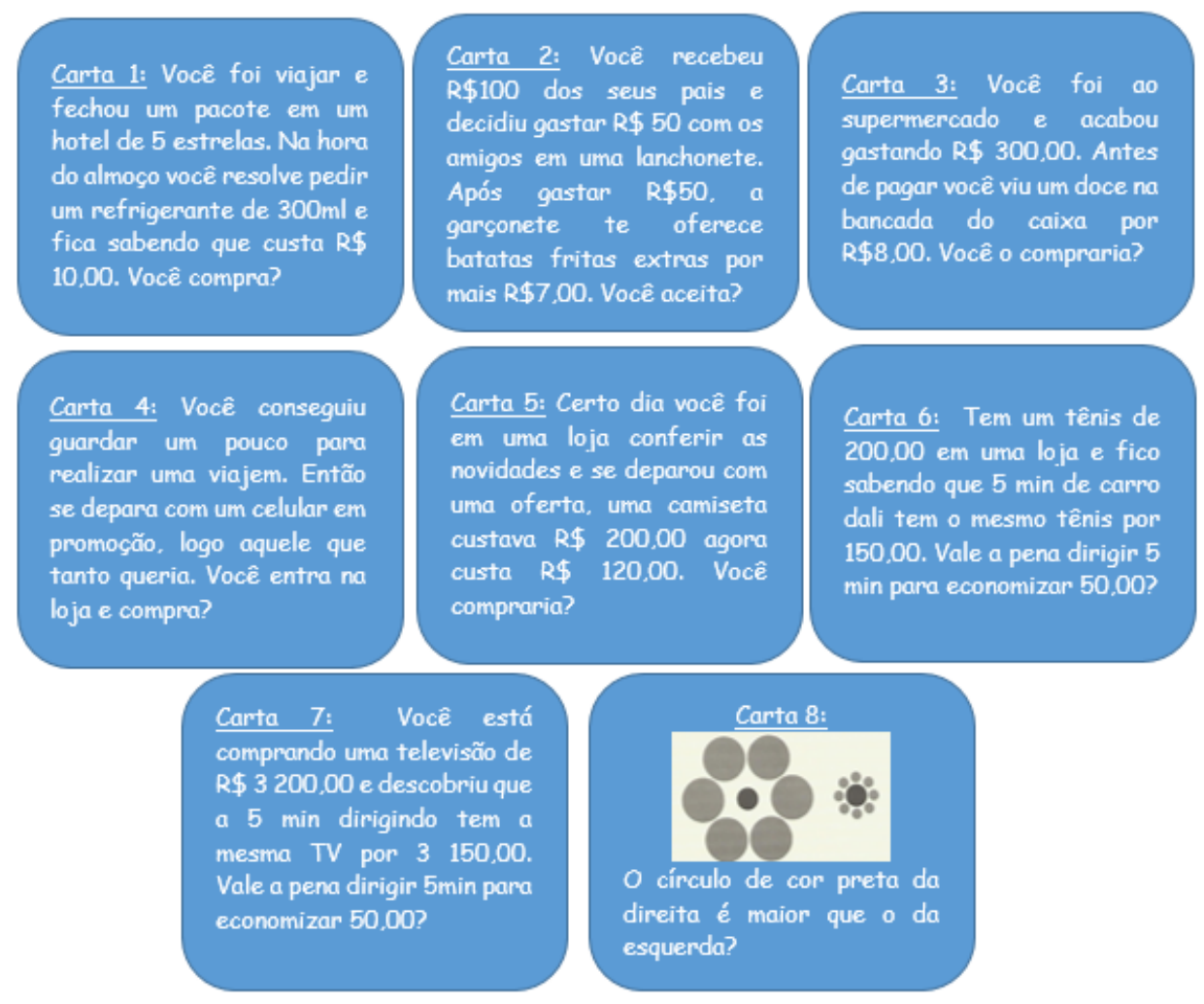

Os participantes são instruídos a ler a situação proposta em cada carta e anotar sua opção "sim” ou “não" no Tabela 1 fornecido. 
Tabela 1.

Atividade 3 - Autogestão - Fase I. Quadro para respostas às cartas do jogo "Conquiste seu sonho!",

\begin{tabular}{|c|c|c|}
\hline \multirow{2}{*}{\multicolumn{3}{|c|}{ Carta 1}} \\
\hline & & \\
\hline Carta 2 & & \\
\hline Carta 3 & & \\
\hline Carta 4 & & \\
\hline Carta 5 & & \\
\hline Carta 6 & & \\
\hline Carta 7 & & \\
\hline Carta 8 & & \\
\hline
\end{tabular}

Tabela 2.

Atividade 3 - Autogestão - Fase I. Respostas esperadas para as cartas do jogo.

\begin{tabular}{lc}
\hline & Respostas \\
\hline Carta 1 & não \\
\hline Carta 2 & não \\
\hline Carta 3 & não \\
\hline Carta 4 & não \\
\hline Carta 5 & não \\
\hline Carta 6 & sim \\
\hline Carta 7 & sim \\
\hline Carta 8 & não \\
\hline
\end{tabular}

$\mathrm{Na}$ fase II da atividade, os participantes são estimulados a refletir sobre o que pensaram ou sentiram durante o jogo. Para isso, foram convidados a redigir um texto orientado pelas três questões que seguem:

1. Quais reflexões o jogo lhe proporcionou?

2. O que você achou das escolhas que fez em cada carta do jogo?

3. Anote os principais pontos que a dupla considerou relevantes para socializar com a turma na roda de conversa.

\section{Análise dos resultados}

O jogo foi praticado em duplas, mas os resultados apresentados foram individuais. $\mathrm{O}$ objetivo do trabalho em duplas foi que houvesse dois momentos de reflexão: (1) troca de informações, discussão e reflexão sobre as respostas por eles apresentadas na dupla e (2) um 
aprofundamento dessa discussão em socialização na roda de conversa, uma vez que cada questão estava associada a uma armadilha psicológica descrita por Ariely e Kreisler (2019).

As questões propostas na fase II foram abertas e a categorização que fizemos é mostrada nas tabelas que seguem.

Tabela 3.

Atividade 3 - Autogestão - Fase I. Respostas dos alunos ao jogo.

\begin{tabular}{cccc}
\hline & Sim & Não & Total \\
\hline Carta 1 & 10 & 14 & 24 \\
\hline Carta 2 & 4 & 20 & 24 \\
\hline Carta 3 & 4 & 20 & 24 \\
\hline Carta 4 & 3 & 21 & 24 \\
\hline Carta 5 & 10 & 14 & 24 \\
\hline Carta 6 & 24 & 0 & 24 \\
\hline Carta 7 & 23 & 1 & 24 \\
\hline Carta 8 & 3 & 21 & 24
\end{tabular}

Conforme o Tabela 2, eram esperadas duas respostas "sim" e seis “não". A Tabela 3 mostra as respostas apresentadas. O maior número de acertos nas respostas esperadas ocorreu nas questões propostas nas cartas 6 e 7. Notamos que na carta 6 todos responderam afirmativamente, em consonância com a resposta esperada, e na carta 7 um respondeu negativamente, quando a resposta esperada era "sim".

A atividade da sequência didática anterior a essa (atividade 2, aqui não discutida) versava sobre cálculo de juros e custo de oportunidade. Solicitava aos alunos que em duplas pesquisassem na internet o preço de alguns produtos de seu interesse. Em seguida, recebiam uma tabela para discutirem após a preencherem com as seguintes informações: produto escolhido, preço à vista, valor de juros, valor final e o que seria considerado custo de oportunidade.

Observamos que os alunos apresentaram evolução nas concepções sobre os problemas de consumo nas questões propostas na atual atividade e supomos que a atividade 2 da sequência didática contribuiu para essa evolução. Refletir sobre o custo de oportunidade desenvolveu 
nesses alunos a capacidade de tomar decisões, mesmo sem ainda conhecerem as armadilhas psicológicas por trás de nossas decisões financeiras, que começaríamos a discutir apenas na atividade 3. Pudemos observar nas respostas à atividade 3 serem poucos os alunos que caíram nas armadilhas psicológicas, frente às concepções manifestadas por eles na roda de conversa no início da atividade 2 . Na primeira roda de conversa, afirmações como "sou muito consumista" e "não consigo guardar dinheiro" foram frequentes.

No entanto, no jogo de cartas apresentado nesta atividade, os estudantes mostraram indícios de utilização do sistema 2, descrito anteriormente, nos termos de Kahneman (2012).

De fato, Ariely e Kreisler (2019) ressaltam que se fosse possível analisar o custo de oportunidade em todas as situações de compra - levar em consideração as alternativas das quais estamos abrindo mão ao optarmos por gastar dinheiro agora - teríamos uma base mais fortalecida para "erguer nossas casas financeiras". De modo racional, dinheiro equivale a custo de oportunidade, que equivale a valor. Mas não somos racionais - pelo contrário: usamos tipos estranhos de truques mentais para descobrir o valor que damos às coisas. Consideramos essas forças, truques e atalhos "sinais de valor". Muitos desses sinais são exatos, outros são enganadores e outros, ainda, são intencionalmente manipuladores. Seguimos esses sinais porque nem sempre é possível analisar os custos de oportunidade, tarefa que se torna ainda mais difícil porque o mundo financeiro está tentando nos confundir e distrair.

Nota-se na discussão desses autores e de outros aqui citados que estamos sempre lutando com forças internas e externas. Consideramos que sem o conhecimento da existência destas forças podemos vivenciar uma luta às cegas. $\mathrm{O}$ conhecimento de tais forças pode se apresentar como uma terceira força capaz de favorecer a tomada de decisões que minimizem os aspectos negativos da má gestão financeira descritos na introdução deste trabalho. 
Problema apresentado na carta 1: Vocêfoi viajar e fechou um pacote em um hotel de 5 estrelas. Na hora do almoço você resolve pedir um refrigerante de $300 \mathrm{ml}$ e fica sabendo que custa $R \$ 10,00$. Você compra?

Nesta questão, como consta na Tabela 3, 10 alunos aceitaram fazer a compra e 14 não. Este problema visa discutir a relatividade em formas históricas, em que os seres humanos têm avaliado incorretamente seus gastos financeiros. Ao fechar um pacote caro em um hotel de cinco estrelas, aceitar comprar um refrigerante por $\mathrm{R} \$ 10,00$ sabendo que habitualmente custa $\mathrm{R} \$$ 3,50 parece ser algo normal, já que se está em um hotel de luxo. O mesmo ocorre em aeroportos e casas de espetáculos, entre outros locais. É razoável refletir que se as pessoas não adquirissem esses produtos superfaturados, o preço poderia seria reajustado.

Em situação de ação neste problema, 10 alunos caíram nessa armadilha, porém 14 se negaram a aceitar a oferta. Quando a professora, na função de mediadora da roda de conversa, perguntou aos que se negaram a comprar o refrigerante porque agiram assim, estes foram unânimes: “Não vale a pena!”. E a socialização das reflexões seguiu conforme as justificativas apresentadas no parágrafo anterior.

Problema apresentado na carta 2: Você recebeu de mesada $R \$ 100,00$ dos seus pais e decidiu gastar $R \$ 50,00$ com os amigos em uma lanchonete. Após gastar $R \$ 50,00$, a garçonete lhe oferece batatas fritas extras por mais $R \$ 7,00$. Você aceita?

Neste problema, quatro alunos responderam afirmativamente e 20 negativamente. Os que responderam "não" justificaram que "não valia a pena aceitar as batatas fritas extras, para cumprir o que eu estabeleci para mim mesmo".

Para os quatro que aceitaram, foi estabelecida a discussão sobre as motivações que nos conduzem ao descontrole financeiro. Temos no cérebro uma região denominada circuito do prazer e da recompensa (o centro acumbente), que comanda nossa necessidade de prazer 
(Cosenza; Guerra, 2011). É importante sentir prazer com a alimentação, pois caso contrário poderíamos esquecer de nos alimentar. No entanto, esse é um centro cerebral que necessita de gestão, pois temos a tendência de querer mais prazer que o necessário para o organismo. Como consequência, pode-se chegar a excessos em diferentes áreas da vida, como por exemplo prejudicar a saúde com alimentação inadequada, passar a usar drogas ilícitas e, ainda, perder a capacidade de sentir prazer em outras coisas saudáveis, tais como bons relacionamentos, ou de sentir gratidão pelo que é positivo na vida, como afeto, beleza da natureza e saúde.

O autocontrole envolve perceber dentro de si os dois sistemas descritos por Daniel Kahneman: o rápido, que é irrefletido, e o mais lento, capaz de ampliar a visão diante de situações financeiras ou de outras que exigem autogestão e segundo Thaler e Shefrin (1981), quando se estabelece regras e essas se tornam hábito, o processo de decisão pode ser evitado devido a uma escolha previamente registrada. Assim, com autoconhecimento pode-se criar regras que tornam o autocontrole natural, parte do nosso dia a dia.

Problema apresentado na carta 3: Você foi ao supermercado e acabou gastando $R \$ 300,00$. Antes de pagar você viu um doce na bancada do caixa por $R \$ 8,00$. Você o compraria?

Nesta situação quatro alunos aceitaram e 20 recusaram, ou seja, 83,33\% exibiram indícios de autocontrole diante de situações de compra. Quando questionados sobre sua decisão, os quatro que aceitaram a oferta relataram:

Aluno 1: Me interessou, porque gosto de doce.

Aluno 2: Estava barato já que tinha gastado 300 nas compras.

Aluno 3: Não resisto a um doce.

Aluno 4: Estava com vontade.

Nesta situação, a armadilha comumente observada é a mesma do primeiro problema, em outro contexto. As ofertas nos caixas de supermercados nos desafiam a resistir às revistas 
de fofocas e a todo tipo de doce usando a mesma abordagem: em relação aos $\mathrm{R} \$ 300,00$ gastos com a compra, $\mathrm{R} \$ 8,00$ a mais em um doce não parecem grande coisa, quando o questionamento deveria ser: Preciso ou não desse produto? (Ariely e Kreisler, 2019).

Na discussão que estabelecemos na roda de conversa, o grupo considerou que o aluno 3 parecia ter agido por impulso, ao passo que apenas o aluno 4 expressou claramente que aceitou a oferta porque queria o doce, mas nenhum deles manifestou preocupação com o custo de oportunidade. Dessa forma, tiveram a oportunidade, em grupo, de pensar e discutir a respeito dos prós e contras de cada situação.

Problema apresentado na carta 4: Você conseguiu guardar um pouco para realizar uma viagem. Então depara com um celular em promoção, uma nova versão incrível do seu que está em bom estado. Você entra na loja e compra?

Três alunos aceitaram comprar o celular e 21 não. O esperado era avaliar a necessidade do produto e seu custo de oportunidade. Ao comprar o celular, a viagem tão almejada é deixada de lado, mas essa troca vale a pena?

Os $87,5 \%$ que optaram por não comprar o celular afirmaram não querer desistir da viagem. A professora, na função de mediadora da roda de conversa, questionou os que aceitaram comprar o aparelho:

P: Então você desistiu da viagem?

Aluno 5: Naquele momento, não pensei que estava desistindo da viagem e considerando o celular mais importante que a viagem.

Aluno 6: Eu também não.

Diante desta situação, podemos supor que os alunos que aceitaram comprar o celular simularam uma compra por impulso, sem pensar no custo de oportunidade e sem exibir autocontrole sobre uma decisão tomada por si mesmos. Assim, esta atividade promoveu a oportunidade de autoconhecimento a esses alunos, em ambiente seguro. Foi relevante o fato de 
que $87,5 \%$ discutiram a temática nas duplas, exibiram amadurecimento nas respostas apresentadas e socializaram suas visões com os demais.

Problema apresentado na carta 5: Certo dia você foi a uma loja conferir as novidades e deparou com uma oferta: uma camiseta que custava $R \$ 200,00$ agora custa $R \$ 120,00$. Você compraria?

Notamos que quando se trata de produtos em promoção a tendência em aceitar foi maior entre os alunos. Dez deles aceitaram a oferta e 14 não. Apesar da alta aceitação, a quantidade de recusas a superou. Alguns dos relatos:

Aluno 7: Não quis comprar porque não estou precisando de uma camiseta.

Aluno 8: Eu aceitei porque o desconto está bom.

Relatos como estes se repetiram ao longo da discussão sobre o problema.

Essa situação refere-se ao tipo de relatividade financeira, nos termos de Ariely e Kreisler (2019), em que não avaliamos o valor real do produto e tendemos a compará-lo com os de outros. Logo, comprar a camiseta aparenta ser vantajoso quando não se pensa no custo de oportunidade: O que estou deixando de lado para comprar esta camiseta? Do que estou abrindo mão? A promoção inicialmente nos cativa, mas é necessário pensar no valor total de R \$ 120,00 a serem gastos e não nos R \$ 80,00 de desconto. Precisamos então comparar esse valor gasto com todas as outras coisas que poderiam ser feitas com esse mesmo valor e examinar se de fato estamos precisando de uma camiseta.

Problema apresentado na carta 6: Há um par de tênis de $R \$ 200,00$ em uma loja e fico sabendo que a 5 min de carro dali há o mesmo par por $R \$ 150,00$. Vale a pena dirigir 5 min para economizar $R \$ 50,00$ ?

Neste problema, todos os alunos aceitaram economizar $\mathrm{R} \$ 50,00$, visto que teriam que dirigir apenas cinco minutos da loja em que estavam. Pesados os prós e contras, o esforço despendido para a economia foi aceito por todos. Diante de uma promoção, observamos nos 
estudantes uma tendência à aceitação, pois haveria uma economia de $\mathrm{R} \$ 50,00$ após poucos minutos ao volante. As respostas apresentadas estão de acordo com o observado em outras pesquisas divulgadas por Ariely e Kreisler (2019). No caso em questão, o valor do produto é $\mathrm{R} \$ 150,00$ e $\mathrm{R}$ \$ 50,00 são economia relativamente significante. Assim, a relatividade foi utilizada pelos estudantes a favor deles, numa aquisição que estava planejada.

Problema apresentado na carta 7: Você está comprando uma TV de $R \$ 3$ 200,00 e descobriu que a 5 min dirigindo há a mesma TV por $R \$ 3$ 150,00. Vale a pena dirigir 5 min para economizar $R \$ 50,00$ ?

Apenas um aluno não aceitou dirigir cinco minutos para obter o desconto e se justificou: "Não vale a pena dirigir cinco minutos para ter um desconto de $\mathrm{R} \$ 50,00$ só". Tal resultado é mais favorável que os obtidos nas pesquisas descritas por Ariely e Kreisler (2019), que apontam que a tendência geral nessa situação é a relatividade enganar. Explicam que isso ocorre porque frente ao valor mais alto da primeira TV o desconto de $\mathrm{R} \$ 50,00$ aparenta ser pouco para compensar dirigir cinco minutos, ao contrário do problema 6 , em que o preço do produto é baixo e o valor do desconto aparenta ser mais vantajoso. Ariely e Kreisler (2019) explicam que em promoções temos a impressão de haver tomado uma decisão inteligente, nem sempre associada ao custo de oportunidade ou ao real valor do produto em si. Assim, a comparação do preço total do produto com o valor do desconto pode influenciar na decisão final e apontar mais uma armadilha de relatividade financeira comum, dado que a economia é a mesma nos dois casos: $\mathrm{R} \$ 50,00$.

Portanto, nos problemas apresentados nas cartas 6 e 7, tendemos a decidir comparando o valor do desconto com o valor total do bem. Segundo Ariely e Kreisler (2019, p. 30), "estimamos o valor de forma que pouco tem a ver com o valor". Comparamos a vantagem relativa do valor informado para o promocional. Assim, no problema 6, comparamos a vantagem relativa do preço do par de tênis, de $\mathrm{R} \$ 200,00$ em uma loja e $\mathrm{R} \$ 150,00$ em outra, 
e tendemos a achar que vale a pena dirigir cinco minutos para economizar $R \$ 50,00$. No problema da carta 7, comparamos a TV de R\$ 3200 com a de R\$ 3150 e tendemos a achar que o esforço para adquirir a segunda não vale a pena, mas nas duas situações o valor poupado é o mesmo. No problema da carta 7, apenas um aluno respondeu negativamente, optando pela escolha de raciocínio fácil ao pensar no valor do desconto com base no preço total da televisão, em vez de analisar o valor real do desconto. Os demais foram capazes de perceber que em ambas as situações estariam economizando o mesmo valor absoluto. As respostas dos alunos às questões 6 e 7 apontam mais um indício de que o trabalho com o conceito de custo de oportunidade na atividade 2 favoreceu o raciocínio dos alunos na realização desta atividade 3 .

Problema apresentado na carta 8: $O$ círculo na cor preta da direita é maior que o da esquerda?

Este problema aborda a relatividade visual. Os alunos compararam a figuras apresentadas na carta (Figura 1) e 21 dos 24 afirmaram que o círculo na cor preta da direita não é maior que o da esquerda. A relatividade permite a comparação das duas imagens, visto que os círculos de cor cinza influenciam visualmente. Segundo Ariely e Kreisler (2019, p. 38), "uma vez que tenhamos enquadrado seus tamanhos dessa maneira, a comparação entre os dois círculos pretos é entre seus tamanhos relativos, e não absolutos."

Ao analisarem a figura, aqueles que responderam corretamente utilizaram estratégias tais como: "vou medir com uma régua para ver se têm o mesmo tamanho" e "vou tampar as bolinhas cinza e comparar apenas as duas pretas". As duplas discutiam a respeito da figura e no momento da roda de conversa relataram: "medimos e vimos que não é maior" e "sem medir parece ser maior", desencadeando assim a discussão. Cada dupla explicou como fez a comparação e uma aluna comentou:

Aluna 9: Essas duas imagens me fizeram lembrar das promoções nas lojas, tipo: em uma loja A pode ter uma bolsa em promoção enquanto os outros produtos da mesma loja estão com preço normal. Já na loja B pode ter essa mesma bolsa, também em 
promoção, com o mesmo preço da loja $\mathrm{A}$, enquanto os outros produtos da loja $\mathrm{B}$ se encontram mais baratos. Se a gente comparar só o produto central, se a gente comparar só o preço da bolsa, vai ver o mesmo preço e não vai perceber a diferença de preço nos outros produtos.

Essa fala promoveu reflexão e análise crítica da figura. Seguiu-se uma rica discussão a respeito da relatividade e a percepção de como ela pode nos influenciar na tomada de decisões.

Tendemos a comparar o círculo de cor preta com os círculos de cor cinza ao redor, e assim temos a ilusão de um ser maior que o outro, porém é necessário comparar os dois círculos pretos entre si. A dificuldade em lidar com a relatividade, segundo os autores aqui descritos, se expressa em nossa tendência em fazer a escolha fácil, utilizando o sistema 1 descrito por Kahneman (2012), que pode nos conduzir a decisões equivocadas e prejudiciais em diversas áreas de nossa vida.

Diante desses resultados, os estudantes identificaram entre si mesmos os que são mais consumistas, os que são equilibrados e os que são econômicos. A atividade apontou a necessidade, entre adolescentes, da discussão que estabeleceram, e a roda de conversa se mostrou essencial para a socialização das opiniões dos mais despertos com os menos despertos nessas questões que influenciam a vida social de todos. Neste caso, os mais despertos atuam como líderes positivos para os menos despertos.

$\mathrm{Na}$ fase II desta atividade, os alunos foram convidados a resumir suas reflexões sobre as questões propostas nas cartas (Figura 1), suscitadas por três questões. A Tabela 4 apresenta a categorização que fizemos das manifestações redigidas pelos estudantes na questão 1 .

Tabela 4.

Atividade 3 -Autogestão-Fase II. Questão 1.

Quais reflexões o jogo lhe proporcionou?

\begin{tabular}{ccc}
\hline Frases utilizadas para resumir & FA & FR \\
\hline Analisar a necessidade & 3 & $25 \%$ \\
\hline Depende do ponto de vista & 1 & $8 \%$ \\
\hline Que sou consumista & 1 & $8 \%$
\end{tabular}




\begin{tabular}{ccc}
\hline Controle financeiro & 5 & $42 \%$ \\
\hline O valor dado ao dinheiro & 1 & $8 \%$ \\
\hline Analisar o custo-benefício & 1 & $8 \%$ \\
\hline Total (duplas) & 12 & $100 \%$ \\
\hline
\end{tabular}

Consideramos que o jogo proporcionou boas reflexões aos participantes. Nas frases por eles utilizadas para resumir o que refletiram, nota-se que $42 \%$ relataram ter refletido sobre a importância do controle financeiro para a tomada de decisões, $25 \%$ afirmaram ter refletido sobre a importância de analisar as necessidades e identificar se é necessário adquirir o produto, $8 \%$ perceberam ser consumistas mediante as atitudes que tiveram e escolhas que fizeram, $8 \%$ declararam ter observado que as escolhas dependem do ponto de vista, do contexto apresentado, do que atrai cada um, e $8 \%$ relataram ter refletido sobre o valor dado ao dinheiro: que é necessário refletir e analisar a relação que temos com o dinheiro diante de situações de consumo e tomadas de decisão.

Dois dos relatos em especial foram: "nesse jogo pude ver meu comportamento financeiro" e "percebi que tenho que ter mais controle financeiro". Estes estudantes relataram que o jogo permitiu a cada um deles analisar suas atitudes e comportamentos financeiros diante de contextos de consumo no dia a dia. Entendemos que esta atividade favoreceu a percepção de suas atitudes e promoveu autoconhecimento.

Analisando-se os percentuais das respostas, nota-se que o controle financeiro apresenta maior valor para esses estudantes. Segundo Ariely e Kreisler (2019), é necessário termos autocontrole para que reconheçamos nossas reais necessidades; é preciso ter força de vontade para resistir às tentações.

Com autocontrole é possível oferecer tempo ao sistema cerebral 2, que é mais lento Kahneman (2012), para não optar pela resposta fácil, e sim distinguir o que é necessário do que é supérfluo, reconhecendo situações em que os enganos são prováveis nas situações financeiras e em outros momentos da vida.

A Tabela 5 sumariza as respostas redigidas pelos alunos para a questão 2 da fase II . 
Tabela 5 .

Atividade 3 - Autogestão - Fase II. Questão 2.

\begin{tabular}{|c|c|c|}
\hline \multicolumn{3}{|c|}{$\begin{array}{l}\text { O que você achou das escolhas que fez no } \\
\text { jogo? }\end{array}$} \\
\hline Autoavaliação & FA & FR \\
\hline Boas & 3 & $25 \%$ \\
\hline $\begin{array}{l}\text { Necessárias e } \\
\text { vantajosas }\end{array}$ & 3 & $25 \%$ \\
\hline $\begin{array}{l}\text { Econômico e } \\
\text { rentável }\end{array}$ & 5 & $42 \%$ \\
\hline $\begin{array}{l}\text { Cauteloso e } \\
\text { econômico }\end{array}$ & 1 & $8 \%$ \\
\hline Total (duplas) & 12 & $100 \%$ \\
\hline
\end{tabular}

Notamos que as questões um e três se mostraram mais eficientes que a dois para suscitar reflexões nos estudantes, pois esta acrescentou apenas as informações registradas na Tabela 5. Faltou solicitar: justifique sua resposta. Podemos considerar ainda, que essa foi uma questão de autoavaliação direta e os estudantes podem não estar habituados para fazer. Passamos à discussão do que se observou na questão três.

Categorizamos e tabulamos os pontos redigidos pelos estudantes, para a questão 3 da fase II na Tabela 6 que segue:

Tabela 6.

Atividade 3 - Autogestão-Fase II. Questão 3.

\begin{tabular}{ccc}
\hline \multicolumn{3}{c}{ Anote os pontos que considera relevantes na atividade } \\
\hline Pontos citados & FA & FR \\
\hline Reflexão sobre necessidade e desejo & 6 & $50 \%$ \\
\hline Consumo & 2 & $17 \%$ \\
\hline Os preços dos produtos & 1 & $8 \%$ \\
\hline Economia & 1 & $8 \%$ \\
\hline Custo de oportunidade & 1 & $8 \%$ \\
\hline Planejamento financeiro & 1 & $8 \%$ \\
\hline Total (duplas) & 12 & $100 \%$
\end{tabular}

Analisando-se os pontos relevantes listados pelos alunos, nota-se que 50\% reconhecem a importância de refletir sobre necessidade e desejo, saber diferenciar o necessário do supérfluo. Já 17\% apontam o aspecto de consumo que é abordado no jogo e 8\% destacam os preços dos produtos, como o preço do refrigerante na carta 1, como um dos pontos relevantes 
na atividade. Outros $8 \%$ consideram relevantes as discussões sobre economia, custo de oportunidade e planejamento financeiro.

Alguns relatos na roda de conversa sobre esta questão expuseram posições comportamentais divergentes entre os estudantes, tais como "foi muito legal o jogo; vi que sou controlador", "tenho que ter mais controle financeiro", "não consigo ver uma promoção e não comprar", "sempre penso se preciso do produto e se vale a pena comprar, "não tenho o costume de pensar, se estou com dinheiro e vontade eu compro". Os estudantes manifestaram diferentes atitudes de consumo e elas puderam ser analisadas e discutidas. Os temas economia, consumo, custo de oportunidade, planejamento financeiro, preços dos produtos, estiveram presentes ao longo da roda de conversa. Observamos que a discussão contribuiu para troca de opiniões entre os estudantes, resultando em comentários como "vou começar a pensar antes de comprar", "tenho que me controlar quando vejo uma promoção as vezes nem preciso e já saio comprando". Este fato denota que além do autoconhecimento, a atividade proporcionou uma reflexão crítica sobre o próprio comportamento, primeiro passo para o consumo consciente.

Diante das situações de consumo proporcionadas pela atividade, os alunos depararam com os aspectos de pagamento e de custo-benefício. Discutiram as táticas publicitárias para estimular o consumo e perceberam que o consumo de determinados produtos pode não compensar.

A possibilidade de fazer melhores escolhas financeiras depende de muitos fatores. $\mathrm{O}$ primeiro deles é conhecer os aspectos do funcionamento humano que interferem nas questões financeiras e as consequências dessa interferência. Por meio das manifestações dos estudantes, pode-se afirmar que adquiriram esse importante conhecimento. A roda de conversa contribuiu para a socialização desse conhecimento e para ampliar a percepção de todos os participantes. Os estudantes consideraram o desenvolvimento desta atividade lúdico e positivo e notamos posteriormente, nos diálogos informais, que já se mostravam mais críticos e reflexivos. 


\section{Considerações finais}

Tornar a aula de matemática mais atrativa é um desafio para os professores. Inserir contextos financeiros é uma forma de abordar a matemática financeira e outros conceitos matemáticos propostos no currículo. As atividades desta pesquisa visaram inserir a educação financeira de maneira que os alunos pudessem refletir, analisando significativamente os cálculos e criticamente os conceitos financeiros e emocionais envolvidos nessas questões.

A aplicação do jogo proporcionou aos alunos o contato com armadilhas financeiras presentes em nosso dia a dia, envolvendo aspectos de matemática financeira, custo de oportunidade, relatividade e gestão das emoções, consciência ambiental, evidenciando a necessidade de trabalhar a autogestão. Ressaltamos que estes temas estão propostos na legislação educacional.

A roda de conversa desempenhou importante papel, permitindo levantar e discutir temas financeiros sugeridos pelos alunos, que puderam manifestar suas opiniões, promovendose assim reflexão sobre temas socioeconômicos de seu cotidiano.

Notamos que os alunos se saíram muito bem nas armadilhas financeiras da atividade 3. Acreditamos que isso se deu pela aplicação da atividade anterior, que abordara o custo de oportunidade. Esse resultado corrobora afirmações de Ariely e Kreisler (2019) sobre a importância da análise do custo de oportunidade. Esses autores afirmam que considerar o custo de oportunidade, antes da aquisição de qualquer bem ou serviço, fornece uma base mais fortalecida para fazer escolhas consequentes.

Consideramos que abordar a educação financeira em contextos do cotidiano dos alunos e a gestão das emoções integradas trouxe aos participantes uma nova perspectiva da temática. Notamos esse fato por meio de comentários tais como: "a escola poderia abordar mais sobre o assunto" e "esse conhecimento vou levar para a vida", dentre outros que nos apontaram que essas atividades trouxeram algum significado para suas vidas. 


\section{Referências}

Ariely, Dan. \& Kreisler, Jeff (2019). A psicologia do dinheiro. Tradução Ivo Korytowski. Editora Sextante.

Bacih, Lilian \& Moran, José (2018). Metodologias ativas para uma educação inovadora: uma abordagem teórico-prática. Editora Penso.

Bauman, Zygmunt (2008). Vida para consumo: a transformação das pessoas em mercadoria. Editora Zahar.

Borges, Paulo Roberto Santana. Educação Financeira: O Novo Perfil Das Famílias a Administração Das Finanças Pessoais. Anais do IX EPCT- Encontro de Produção $\begin{array}{lll}\text { Científica } & e & \text { Tecnológica, }\end{array}$ http://www.fecilcam.br/nupem/anais_ix_epct/PDF/TRABALHOSCOMPLETO/Anais -CSA/19.pdf .

Brasil, Ministério da Educação. Base Nacional Comum Curricular. http://portal.mec.gov.br/index.php?option=com_docman\&view $=$ download\&alias $=851$ 21-bncc-ensino-medio\&category_slug=abril-2018-pdf\&Itemid=30192.

Cosenza, R.M.; \& Guerra, L. B. (2011). Neurociência e Educação: como o cérebro aprende. Editora Artmed.

Cracasso, S.(2016). Curso de capacitação em Educação Emocional. Universidade Federal de São Paulo: Laboratório Interdisciplinar de Neurociências Clínicas.

Estratégia Nacional de Educação Financeira (ENEF). Quem somos. http://www.vidaedinheiro.gov.br/quemsomos/.

Kahneman, Daniel (2012). Rápido e Devagar: duas formas de pensar. Tradução de Cássio de Arantes Leite. Editora Objetiva.

Layard, Richard (2008). Felicidade: Lições de uma nova ciência. Tradução de Maria Clara De Biase W. Fernandes. Editora BestSeller.

Serasa Experian. Inadimplência do consumidor atinge 61,6 milhões, revela Serasa. https://www.serasaexperian.com.br/sala-de-imprensa/inadimplencia-do-consumidoratinge-616-milhoes-revela-serasa.

Serasa Experian. Jovem é perfil que menos controla a vida financeira. http://noticias.serasaexperian.com.br/jovem-e-o-perfil-que-menos-controla-a-vidafinanceira/.

Thaler, Richard H., \& Sunstein, Cass R. (2019) Nudge: como tomar melhores decisões sobre saúde, dinheiro e felicidade. Editora Objetiva.

Thaler, Richard H., \& Shefrin, H, M. (1981) An Economic Theory of Self-Control. Journal of Political Economy, vol. 89, no. 2, 392-406.

Recebido em: 24/03/2021

Aprovado em: 08/12/2020 